\title{
Developing Communication Competencies Through E-Learning: The Motivating Potential of Adaptive Video Role Play
}

\author{
Djoerd Hiemstra $^{a}$ and Anne Zagt ${ }^{\text {b }}$ \\ ${ }^{a}$ Simulation \& Game-Based Learning Lab (SiGa-Lab), ${ }^{b}$ NHL University of Applied \\ Sciences, The Netherlands.
}

\begin{abstract}
To develop competence through e-learning tools, students must be motivated to use these tools. Hence, we conducted two empirical studies to explore the motivating potential of an adaptive video role playing game (AVR) for training communication competencies. In Study $1(N=54)$, we used a withinperson design to examine students' motivation in three learning conditions: in the classroom, when playing the AVR, and when doing homework. The results showed that, relative to the homework condition, in the AVR condition students were higher in perceived competence, relatedness, intrinsic motivation, and flow. No difference between the classroom condition and the AVR condition were found. In Study $2(N=150)$, we used a randomized experimental design to examine the motivational consequences of using videos (AVR) rather than photos (APR) in the adaptive role playing game. We found that, relative to students in the APR condition, students in the AVR condition were higher in relatedness and flow. No differences in perceived competence, autonomy, and intrinsic motivation were observed. We conclude that an AVR may have considerable motivational benefits relative to common homework assignments, and some motivational benefits relative to an APR.
\end{abstract}

Keywords: e-learning, video role play, games, motivation, flow 


\section{Introduction}

In a knowledge-intensive service economy, it is imperative that professionals possess excellent communication competencies. Indeed, employers and experts frequently assert that educational institutions should focus more on the development of these generic $21^{\text {st }}$ century competencies (Dede, 2009; Silva, 2009; Voogt \& Roblin, 2012). Such demands for more training in specific areas naturally create a dilemma for education programmes: how to find the time and resources within the existing curriculum? Developing communication competencies requires deliberate practicing (Ericsson, 2006). A common training method is role play training, which entails that students' rehearse communication scenario's, typically with the help of actors, and receive personal feedback from a skilled trainer. This is a labour-intensive and expensive form of education (Schönrock-Adema, 2002). Therefore, there is a need for smart solutions to increase students' deliberate practicing time at acceptable costs (Rotherham \& Willingham, 2010). Online adaptive video role playing games (AVR) could potentially offer a solution. One example of such an application is the Communication Styles Game, developed by GITP. This is an online AVR that allows participants to practise a variety of communication styles in a simulated environment outside of classroom. For effective implementation of such an AVR in education, it is essential that students are motivated to spend many hours practising with the AVR independently. Hence, an important question is whether AVRs motivate students to learn. Although it is often assumed that the use of new technology in education can have a motivating effect (Prensky, 2001), there is very little empirical information available to support this. Therefore, we examined the motivating potential of the Communication Styles Game. In two complementary studies, we addressed the following questions: (1) What is the added value of the AVR, relative to more traditional forms of education: Do students perceive playing the Communication Styles Game as more motivating than receiving classroom instruction or doing common homework assignments? (2) What is the added value of using video technology with AVR: Do students perceive working with the video version of the Communication Styles Game as more motivating than working with the simplified photo version of the same game?

Below, we first explain the concepts AVR and motivation. We then present the results of the two studies. Finally, we present the discussion and recommendations. 


\subsection{Adaptive Video Role Play}

In AVRs, players are placed in a simulated environment in which they control a character or avatar, while playing through a scenario in which problems need to be solved. Players need to use their knowledge and skills to determine which solution is appropriate. Depending on the player's behaviour in the game, he or she will perform better or worse in achieving certain goals (Feinstein, Mann \& Corsun, 2002). In the AVR that was used in the present studies (i.e., the Communication Styles Game), the player takes on the role of project manager from a first person perspective. The task is to organise an event with a team of colleagues. The scenario is composed of a sequential series of video clips. After each clip, the player is presented with a choice of responses. Each response corresponds to one style from the communication styles model (Van der Horst, Hoogstraten, Meyer, Serlie, Wanrooy, 2010; cf., Merrill \& Reid, 1981): directive (i.e., taking space, businesslike), expressive (i.e., taking space, personal), cooperative (i.e., giving space, personal), or reflective (i.e., giving space, businesslike). The aim of the game is to connect as closely as possible with the communication style of the conversation partners. The better the player performs in this regard, the more effectively the conversations proceed. After the game ends, the player receives information about the extent to which he or she has applied the various communication styles, and the extent to which he or she has succeeded in connecting with the conversation partners.

\subsection{Motivation}

Motivation refers to the cognitive factors and processes whereby goal-directed activities are instigated and sustained (Schunk, Meece \& Pintrich, 2014). To gain insight into the motivating effect of the Communication Styles Game, we measured five variables that, according to self-determination theory (Ryan \& Deci, 2000), and flow theory (Csikszentmihalyi, 1975), play an important role in individuals' motivation: (1) perceived competence, (2) autonomy, (3) relatedness, (4) intrinsic motivation, and (5) flow. Perceived competence refers to the degree to which individuals believe to be good at something. Autonomy refers to the degree to which individuals feel free to determine their own actions. Relatedness refers to the extent to which individuals experience satisfactory relationships with others. Intrinsic motivation entails that individuals engage in an activity because they derive pleasure and satisfaction from performing the activity. Flow refers to the state of immersion that individuals may experience when they are optimally motivated. 


\subsection{The Present research}

In two empirical studies we explored the motivating potential of an online adaptive video role playing game (AVR): the Communication Styles Game. In Study $1(N=54)$, we used a within-person design to compare students' motivation in three learning conditions: in the classroom, when playing the AVR, and when doing common homework. In Study 2 ( $n=$ 150), we used a randomized experimental design to examine the motivational consequences of using video's rather than photo's in the role playing game. Because of the explorative nature of the studies, no a priori hypotheses were articulated.

\section{Study 1: The Added Value of AVR in Education}

The objective of study 1 was to gain insight into the motivating potential of the AVR, in comparison to classroom instruction and homework assignments.

\subsection{Method Study 1}

Participants. The participants in the study were 54 students of an university of applied sciences in the Netherlands who were following a course in communication skills that included classroom instruction, playing the AVR, and doing common homework assignments.

Procedure. Upon completion of the course, the participants filled in a short questionnaire in which they indicated their motivation in each condition (i.e., in the classroom, when playing the AVR, and when doing common homework).

Measures. Perceived competence, relatedness, autonomy, intrinsic motivation, and flow were measured using single questionnaire items. On a scale ranging from 1 (strongly disagree) to 7 (strongly agree), the participants indicated to which extend a statement applied to them (e.g., "While playing the Communication Styles Game I felt competent"). 


\subsection{Results Study 1}

The means and standard deviations of the five motivation variables, by learning condition are shown in Table 1. The results indicate a difference in participants' motivation across the three conditions. A multivariate analysis of variance with repeated measures (RMMANOVA), with the learning condition as the independent variable and the five motivation variables as dependent variables, showed a significant overall effect, $F(2,4)=8.06, p<$ $0.01, \eta^{2}=0.13$. As indicated by the superscripts in Table 1, pairwise comparisons between the conditions indicated that the participants perceived playing the AVR as equally motivating as classroom instruction: no significant differences on any of the motivation variables were found. Further, for all five variables, the participants perceived classroom instruction as more motivating than homework assignments: we found significant differences in perceived competence, autonomy, relatedness, intrinsic motivation and flow. Furthermore, for four of the five variables, the students perceived playing the AVR as more motivating than homework assignments: we found significant differences in perceived competence, relatedness, intrinsic motivation and flow, but not in autonomy.

\begin{tabular}{lcccccc}
\hline & \multicolumn{2}{c}{ Classroom $(\mathrm{n}=54)$} & \multicolumn{2}{c}{ AVR $(\mathrm{n}=54)$} & \multicolumn{2}{c}{ Homework $(\mathrm{n}=54)$} \\
\cline { 2 - 7 } & $M$ & $S D$ & $M$ & $S D$ & $M$ & $S D$ \\
\hline Perceived competence & $4.19^{\mathrm{a}}$ & 1.48 & $4.26^{\mathrm{a}}$ & 1.48 & $3.83^{\mathrm{b}}$ & 1.50 \\
Autonomy & $3.93^{\mathrm{a}}$ & 1.64 & $3.68^{\mathrm{ab}}$ & 1.73 & $3.44^{\mathrm{b}}$ & 1.42 \\
Relatedness & $4.44^{\mathrm{a}}$ & 1.62 & $3.96^{\mathrm{a}}$ & 1.71 & $3.13^{\mathrm{b}}$ & 1.45 \\
Intrinsic motivation & $4,30^{\mathrm{a}}$ & 1.55 & $4.08^{\mathrm{a}}$ & 1.64 & $3.63^{\mathrm{b}}$ & 1.48 \\
Flow & $4.02^{\mathrm{a}}$ & 1.63 & $4.25^{\mathrm{a}}$ & 1.76 & $3.43^{\mathrm{b}}$ & 1.51 \\
\hline
\end{tabular}

Table 1. Means and Standard Deviations on the Motivation Variables, by Learning Condition

Note. Within each row, different superscripts indicate significant condition differences at level $p<.05$

\subsection{Conclusions Study 1}

The results of Study 1 indicate that that the motivating power of the AVR was similar to that of the classroom instructions, but stronger than that of the common homework assignments. We therefore conclude that AVR may be of added value for education relative to common homework assignments. 


\section{Study 2: The Added Value of Video in Role Playing Games}

A major drawback of AVRs is the relatively high costs of development. An interesting question is therefore, whether a similar effect can be achieved with simpler role-playing games, where scenarios are shown using photo's instead of videos. This would make it easier and cheaper for educational institutions to develop such games themselves. Therefore, we conducted a randomised experiment in which we contrasted the video version of the Communication Styles Game (AVR condition) with a photo version (APR condition) of the same game. In each condition we assessed participants motivation on the same five variables as in Study 1 (i.e., perceived competence, relatedness, autonomy, intrinsic motivation, and flow).

\subsection{Method Study 2}

Participants. The participants were 150 students of an university of applied sciences who volunteered to participate in the study.

Procedure. The participants were randomly assigned to the AVR or to the APR condition. In each condition, after playing the game, the participants filled in a questionnaire in which they indicated their motivation while playing the game.

Measures. Perceived competence, autonomy and relatedness were measured using the Basic Psychological Needs Scale (La Guardia, Ryan, Couchman \& Deci, 2000). Response categories ranged from 1 (strongly disagree) to 5 (strongly agree). Intrinsic motivation was measured on the Academic Motivation Scale (Vallerand, 1997). Flow was measured using the Flow Scale (Barzilai \& Blau, 2014). Response categories ranged from 1 (strongly disagree) to 7 (strongly agree).

\subsection{Results Study 2}

The means and standard deviations on the five motivation variables, by type of role play game (i.e., AVR versus APR) are shown in Table 2. The results show a difference in motivation between the two conditions. A MANOVA with type of role play game as the independent variable and the five motivation variables as dependent variables yielded a significant overall effect, $F(5,144)=3.19, p<0: 01, \eta^{2}=0.10$. Post-hoc analyses showed that, relative to the participants who played the APR version of the game, the participants who played the AVR version of the game were higher in relatedness and flow. No differences in perceived competence, autonomy, and intrinsic motivation were found. 


\begin{tabular}{lcccc}
\hline & \multicolumn{2}{c}{ AVR (n=69) } & \multicolumn{2}{c}{ APR (n=81) } \\
\cline { 2 - 5 } & $M$ & $S D$ & $M$ & $S D$ \\
\hline Perceived competence & $3.72^{\mathrm{a}}$ & .42 & $3.62^{\mathrm{a}}$ & .52 \\
Autonomy & $3.18^{\mathrm{a}}$ & .72 & $3.24^{\mathrm{a}}$ &, 78 \\
Relatedness* & $3.61^{\mathrm{a}}$ & .61 & $3.34^{\mathrm{b}}$ & .72 \\
Intrinsic motivation & $4.44^{\mathrm{a}}$ & 1.02 & $4.67^{\mathrm{a}}$ & 1.09 \\
Flow* & $4.74^{\mathrm{a}}$ & 1.08 & $4.27^{\mathrm{b}}$ & 1.46 \\
\hline
\end{tabular}

\section{Table 2. Means and Standard Deviations on the Motivation Variables, by Type of Role Playing Game}

Note. Within each row, different superscripts indicate significant condition differences at level $p<.05$

\subsection{Conclusions Study 2}

The results of Study 2 indicate that the motivating power of the video version (AVR) of the online adaptive role playing game is higher, relative to the photo version (APR) of the same game. However, the differences concern only two of the five motivation variables. We therefore conclude that using videos rather than photos in online adaptive role play games may have some added value.

\section{Discussion and recommendations}

First, based on our research, we conclude that AVRs such as the Communication Styles Game can motivate students to learn. The motivating effect of the Communication Styles Game is similar to that of classroom instructions but higher than that of homework assignments. It is therefore plausible that AVRs could be successfully employed as a blended learning tool, to increase the deliberate practicing time of students outside classroom instruction. A note is the relatively low number of participants $(N=54)$ in Study 1 , which may limit the generalizability of our findings. However, our conclusions are in line with previous research suggesting that e-learning tools should preferably be used to supplement rather than to substitute regular instruction (Liao, 1998; Tamim, Bernard, Borokhovski, Abrami \& Schmid, 2011).

Second, we conclude that the use of videos in role play games (AVR) provides some added value when compared to using photos (APR). Because we used a randomized experimental design, we are confident that the differences in motivation are caused by the use of video rather than photos. These findings are in line with research indicating that media-rich learning materials are typically more effective relative to media-poor learning materials 
(Mayer, 1989; Liu, Liao \& Pratt, 2009). It is important to note, however, that we only found significant differences on two of the five motivation variables. Given the considerably lower development costs of photo role-playing games (APR), it may therefore still be worth considering the use APRs in education. More research is desirable in this regard. Education needs affordable and effective tools that can encourage students to spend more time and energy developing their competences. Online adaptive role playing games may contribute to this aim. In particular, when used as a supplement to common homework assignments.

\section{References}

Barzilai, S., \& Blau, I. (2014). Scaffolding game-based learning: Impact on learning achievements, perceived learning, and game experiences. Computers \& Education, 70, 65-79.

Csikszentmihalyi, M. (1975). Beyond boredom and anxiety. San Francisco: Jossey-Bass.

Dede, C. (2009). Comparing frameworks for "21 century skills". Harvard: Harvard Graduate School of Education.

Ericsson, K. A. (2006). The influence of experience and deliberate practice on the development of superior expert performance. In Ericsson, K. A., Charness, N., Feltovich, P.J. \& Hoffman, R.R. (2006). The Cambridge handbook of expertise and expert performance (pp. 685-705). Cambridge: Cambridge University Press.

Feinstein, A.H., Mann S., \& Corsun, D.L. (2002). Charting the experiential Territory. Clarifying definitions and uses of computer simulation, games, and role play. Journal of Management Development, 10, 732-744.

La Guardia, J. G., Ryan, R. M., Couchman, C. E., \& Deci, E. L. (2000). Within-person variation in security of attachment: A self-determination theory perspective on attachment, need fulfilment, and well-being. Journal of Personality and Social Psychology, 79, 367-384.

Liao, Y. K. C. (1998). Effects of hypermedia versus traditional instruction on students' achievement: A meta-analysis. Journal of Research on Computing in Education, 30, 341-359. In Hattie, J. A.C. (2009). Visible Learning. A synthesis of over 800 metaanalyses relating to achievement. London: Routledge Taylor \& Francis Group.

Liu, S., Liao, H., \& Pratt, J. A. (2009). Impact of media richness and flow on e-learning technology acceptance. Computers \& Education, 52, 599-602.

Mayer, R. E. (1989). Systematic thinking fostered by illustrations in scientific text. Journal of Educational Psychology, 81, 240-246. In Hattie, J. A.C. (2009). Visible Learning. A synthesis of over 800 meta-analyses relating to achievement. London: Routledge Taylor \& Francis Group.

Merrill, D.W., \& Reid, R.H. (1981). Personal styles and effective performance. Pennsylvania: Chilton Book Company.

Prensky, M. (2001). Digital natives, digital immigrants. On the Horizon, 9, 1-6. 
Rotherham, A.J., \& Willingham, D. (2009). $21^{\text {st }}$-Century" Skills. The Challenges Ahead. Educational Leardership, 67, 16 - 21.

Ryan, R. M., \& Deci, E. L.(2000). Self-determination theory and the facilitation of intrinsic motivation, social development, and well-being. American Psychologist, 55, 68-78.

Schönrock-Adema, J. (2002). De ontwikkeling en evaluatie van een zelfinstructieprogramma voor een training in basisgespreksvaardigheden. Groningen: Rijksuniversiteit Groningen.

Schunk, D. H., Meece, J. R., \& Pintrich, P. R. (2014). Motivation in education: theory, research, and applications. Boston: Pearson.

Silva, E. (2009). Measuring skills for $21^{\text {st }}$ century learning. Phi Delta Kappan, 90, 630-634.

Tamim, R.M., Bernard, R.M., Borokhovski, E., Abrami P.C. \& Schmid, F. (2011). What forty years of research says about the impact of technology on learning: a second-order meta-analysis and validation study. Review of Educational Research. 81 .

Vallerand, R. J. (1997). Toward a hierarchical model of intrinsic and extrinsic motivation. Advances in Experimental Social Psychology, 29, 271-360.

Van der Horst, A., Hoogstraten H., Meyer, H. Serlie, A., Wanrooy, M. (2010). Groot Psychologisch Modellenboek. Culemborg: Van Duuren Management.

Voogt, J., \& Roblin, N. P. (2012). A comparative analysis of international frameworks for $21^{\text {st }}$ century competences: implications for national curriculum policies. Journal of Curriculum Studies, 44, 299-321. 